\title{
Postoperative radiotherapy for prostate cancer
}

\author{
Morbidity of local-only or local-plus-pelvic radiotherapy
}

\author{
Cora Waldstein $^{1} \mathbb{D} \cdot$ Wolfgang Dörr $^{1,2} \cdot$ Richard Pötter $^{1} \cdot$ Joachim Widder $^{1} \cdot$ Gregor Goldner $^{1}$
}

Received: 5 July 2017 / Accepted: 30 August 2017 / Published online: 19 September 2017

(C) The Author(s) 2017. This article is an open access publication.

\begin{abstract}
Purpose The aim of this work was to characterise actuarial incidence and prevalence of early and late side effects of local versus pelvic three-dimensional conformal postoperative radiotherapy for prostate cancer.

Materials and methods Based on a risk-adapted protocol, 575 patients received either local $(n=447)$ or local-pluspelvic $(n=128)$ radiotherapy. Gastrointestinal (GI) and genitourinary (GU) side effects ( $\geq$ grade 2 RTOG/EORTC criteria) were prospectively assessed. Maximum morbidity, actuarial incidence rate, and prevalence rates were compared between the two groups.

Results For local radiotherapy, median follow-up was 68 months, and the mean dose was $66.7 \mathrm{~Gy}$. In pelvic radiotherapy, the median follow-up was 49 months, and the mean local and pelvic doses were 66.9 and 48.3 Gy respectively. Early GI side effects $\geq \mathrm{G} 2$ were detected in $26 \%$ and $42 \%$ of patients respectively $(p<0.001)$. Late GI adverse events were detected in $14 \%$ in both groups $(p=0.77)$. The 5 -year actuarial incidence rates were $14 \%$ and $14 \%$, while the prevalence rates were $2 \%$ and $0 \%$ respectively. Early $\mathrm{GU} \geq \mathrm{G} 2$ side effects were detected in $15 \%$ and $16 \%$ ( $p=$ 0.96 ), while late GU morbidity was detected in $18 \%$ and $24 \%(p=0.001)$. The 5 -year actuarial incidence rates were
\end{abstract}

Cora Waldstein, MD

cora.waldstein@meduniwien.ac.at

1 Department of Radiation Oncology, Comprehensive Cancer Center, General Hospital of Vienna, Medical University of Vienna, Währinger Gürtel 18-20, 1090 Vienna, Austria

2 Christian-Doppler Laboratory for Medical Radiation Research for Radiooncology, Medical University of Vienna, Vienna, Austria
$16 \%$ and $35 \%(p=0.001)$, while the respective prevalence rates were $6 \%$ and $8 \%$.

Conclusions Despite the low prevalence of side effects, postoperative pelvic radiotherapy results in significant increases in the actuarial incidence of early GI and late GU morbidity using a conventional 4-field box radiotherapy technique. Advanced treatment techniques like intensitymodulated radiotherapy (IMRT) or volumetric modulated arc radiotherapy (VMAT) should therefore be considered in pelvic radiotherapy to potentially reduce these side effects.

Keywords Survival analysis - Genitourinary system · Toxicity - Gastrointestinal tract - Actuarial incidence rate

\section{Postoperative Strahlentherapie beim Prostatakarzinom}

Morbidität nach lokaler Radiatio vs. lokaler Radiatio und Beckenbestrahlung

\section{Zusammenfassung}

Ziel Ziel der vorgestellten Arbeit ist es, die Häufigkeit früher und später Nebenwirkungen nach postoperativer Bestrahlung von Prostatakarzinompatienten zu analysieren. Verglichen wurden dabei die Nebenwirkungen von lokaler Bestrahlung mit denen nach lokaler Bestrahlung plus Beckenbestrahlung (4-Felder-Box-Technik).

Material und Methoden Basierend auf einem risikoadaptierten Protokoll erhielten 575 Patienten nach Prostatektomie entweder eine konventionelle lokale Bestrahlung ( $n=$ $447)$ oder eine Beckenbestrahlung $(n=128)$. Gastrointestinale und urogenitale Nebenwirkungen $\geq$ Grad 2 wurden prospektiv anhand der RTOG/EORTC-Klassifikation erhoben. Verglichen wurden die maximale Morbidität sowie die 
aktuarischen Inzidenz- und Prävalenzraten in beiden Gruppen.

Ergebnisse Bei lokaler Bestrahlung waren die mediane Nachsorgezeit 68 Monate und die mittlere Dosis 66,7 Gy, bei Beckenbestrahlung waren die mediane Beobachtungszeit 49 Monate und die lokale Dosis bzw. die Beckendosis 66,9 und 48,3 Gy. Frühe gastrointestinale Nebenwirkungen wurden bei $26 \%$ (lokal) bzw. bei $42 \%$ (Becken) beobachtet ( $p<0,001)$, eine späte gastrointestinale Morbidität bei jeweils $14 \%$ in beiden Gruppen $(p=0,77)$. Die aktuarischen Fünfjahresinzidenzraten waren 14 bzw. $14 \%$, die Prävalenz lag bei 2 bzw. $0 \%$. Frühe urogenitale Nebenwirkungen wurden bei 15 bzw. $16 \%$ beobachtet $(p=0,96)$, eine späte urogenitale Morbidität bei 18 bzw. $24 \%(p=0,001)$. Die aktuarischen Fünfjahresinzidenzraten betrugen 16 bzw. $35 \%$, während die Prävalenz bei 6 bzw. $8 \%$ lag.

Schlussfolgerung Trotz der generell niedrigen Prävalenz strahlenbedingter Nebenwirkungen führte die konventionelle 4-Felder-Box-Beckenbestrahlung zu einem signifikanten Anstieg der aktuarischen Inzidenz früher gastrointestinaler und später urogenitaler Nebenwirkungen in der postoperativen Behandlung von Patienten mit Prostatakarzinom. Bei der Bestrahlung von Beckenfeldern sollten daher moderne Techniken wie VMAT (,,volumetric modulated arc radiotherapy“) oder IMRT (,,intensity-modulated radiotherapy“) zum Einsatz kommen, sodass diese Nebenwirkungen potenziell verringert werden.

Schlüsselwörter Überlebensanalyse · Urogenitalsystem · Toxizität · Gastrointestinaltrakt · Aktuarische Inzidenzrate

Postoperative radiotherapy for prostate cancer ( $\mathrm{PCa}$ ) is currently regarded as standard of care in patients with an increased risk for recurrence after radical prostatectomy (RP). Typical risk factors are infiltration of the seminal vesicles, extraprostatic extension, positive surgical margins, a high Gleason Score or a high pre-RP prostate-specific antigen (PSA) level [1, 2].

Three randomised studies (SWOG 8794, EORTC 22911, ARO 96-96/AUOAP 09/95) demonstrated improved biochemical recurrence-free survival with local adjuvant radiotherapy compared with surgery alone [3-7]. Moreover, long-term follow-up of the SWOG S8794 trial showed improved overall survival for patients with pT3N0M0 PCa [4]. However, about $25 \%$ of the patients will suffer biochemical failure even after receiving adjuvant local radiotherapy. Therefore, extending the postoperative treatment volume to include pelvic lymph nodes has been suggested based on the assumption that patients with an increased risk of lymph node involvement could benefit from elimination of microscopic disease [8, 9].
However, the role of elective radiotherapy of the pelvic nodal regions in clinically node-negative patients is controversial [10-12], since side effects may be more frequent and clinical benefit has not yet been established definitively. As the median life-expectancy after treatment for $\mathrm{PCa}$ is 13.8 years [13], it is particularly important to carefully assess long-term toxicity after pelvic radiation.

After radiotherapy for prostate cancer, urinary and bowel urgency and/or incontinence, as well as dysuria and rectal bleeding are the most frequently reported side effects [14-19]. Due to the increased irradiated volume in pelvic lymph node radiotherapy, an increased incidence and/or severity and/or an extended duration of adverse events may be expected. For primary external beam radiation therapy, RTOG 9413 compared the toxicity between prostate only and whole pelvic radiotherapy using three-dimensional (3D) conformal techniques, and a nonsignificant increase in the rate of early and late toxicity was observed after whole pelvic radiotherapy (WPRT) [20, 21]. However, toxicity data in the postoperative setting comparing pelvic and local-only radiotherapy are scarce.

The aim of the present study was to investigate the difference in terms of incidence and prevalence rates as well as the duration of late side effects between local and pelvic postoperative external beam radiation therapy in the treatment of PCa. We used monocentric prospectively assessed data of a consecutive cohort of postoperative patients undergoing local or pelvic radiotherapy based on an institutional risk-adapted protocol and being followed-up for up to 15 years. Side effects were prospectively evaluated at regular time intervals according to European Organization for Research and Treatment of Cancer/Radiation Therapy Oncology Group (EORTC/RTOG) criteria in a standardised fashion.

\section{Patients and methods}

\section{Patients}

In this prospective cohort study, 961 patients received postoperative radiotherapy between 1994 and 2011. In general, patients underwent radical prostatectomy combined with standard lymphadenectomy, which is limited to the obturator fossa and/or external iliac lymph nodes and typically comprised removal of 3-4 lymph nodes. Androgen deprivation therapy was given to high-risk patients, if one or more of the following factors was present: prostate-specific antigen (PSA) score $>20 \mathrm{ng} / \mathrm{ml}$ at baseline, Gleason score of $8-10$, or clinical stage $\mathrm{T} 2 \mathrm{C}$ or higher.

According to our institutional policy, the Roach formula estimating the probability of lymph node involvement in the primary setting was employed to make the indication for 
WPRT using baseline data prior to surgery (cutoff, lymph node involvement probability $\geq 15 \%$ ) [22]. Patients with an unknown Gleason Score but with a high grading (G3) or a high PSA value prior to radiotherapy $(\geq 20 \mathrm{ng} / \mathrm{ml})$ also received WPRT. Patients who had a low risk of lymph node involvement $(<15 \%)$ or who were 80 years or older or who had a history of inflammatory bowel disease, a history of colorectal surgery, or a Karnofsky performance score < $80 \%$ received local radiotherapy only. Before entry, all patients underwent bone scintigraphy, CT or MRI scans of the abdomen and the pelvis and PSA testing. Participants with pathologically positive lymph nodes $(n=59)$, distant metastases $(n=19)$, alternative radiotherapy techniques $(n=$ $17)$ or with a follow-up of less than 18 months $(n=274)$ were excluded. In addition, patients with local radiation doses $<65 \mathrm{~Gy}(n=14)$, those with pelvic radiation doses $<45$ Gy $(n=2)$, or $>50.4$ Gy $(n=1)$ were excluded. Thus, 447 pathologically node-negative patients receiving local radiotherapy and 128 patients receiving local-plus-pelvic lymph node radiotherapy were included in the current analysis.

\section{Radiotherapy}

All patients were treated using a 3-dimensional four-field box technique with individualised collimation. The target volume was delineated according to ICRU-report 62 [23]. For patients undergoing local radiotherapy, the clinical target volume (CTV) included the prostate bed. For patients undergoing pelvic nodal radiotherapy, the CTV included the prostate bed and the iliac internal, external and communis lymph nodes up to the aortic bifurcation. The safety margin around the CTV for both groups was $10-12 \mathrm{~mm}$ in all directions. Both groups received a dose of $65-74 \mathrm{~Gy}$ in 1.8-2 Gy fractions to the prostate bed, and the patients with pelvic radiotherapy received an additional 45-50.4 Gy in 25-28 fractions to the pelvic lymph nodes.

\section{Morbidity assessment}

Patients were seen weekly or every two weeks during radiotherapy, every 3-6 months for the first year after radiotherapy and at least once per year thereafter. Gastrointestinal (GI) and genitourinary (GU) side effects were prospectively scored by a study physician according to EORTC/ RTOG criteria [24]. Early side effects were assessed until 3 months after the end of radiotherapy. GI symptoms included stool frequency, stool consistency, faecal incontinence, rectal pain, cramping, rectal mucous discharge, urgency of defecation and rectal bleeding. GU side effects included frequency, urgency, incontinence, dysuria and haematuria [24]. The durations of late GI and GU side effects of grade $\geq 2$ were calculated from first diagnosis to their last occurrence.

\section{Statistical analysis}

To estimate the risk of developing a defined maximum grade of side effects at least once at any time-point during followup, reporting actuarial incidence rates is a common practice [25]. However, actuarial incidence rates alone do not provide any information about the duration or the possibility of recovery of the assessed side effects. Prevalence rates indicating the relative percentage of patients suffering from late side effects at a defined time-point, may provide clinically more meaningful information [26-30].

As the competing risk (death) was negligibly low $(<8 \%$ over a period of more than 10 years), actuarial incidence rates of GI and GU side effects of grade $\geq 2$ were calculated using the Kaplan-Meier method, and differences between curves were estimated using the log-rank statistic. Maximum morbidities were tabulated and compared using the chi square $\left(\chi^{2}\right)$ test. In addition, the prevalence of side effects of grade $\geq 2$ was calculated for each followup time-point and compared using Fisher's exact test. The duration of side effects was statistically analysed using unpaired t-tests. All time parameters were calculated from the last day of radiotherapy. Calculations were performed using Prism Version 4 (GraphPad Software, Inc., San Diego, CA, USA). The significance level was set at $p<0.05$.

\section{Results}

A total of 575 patients were included in this analysis. For patients undergoing local radiotherapy $(n=447)$, the median follow-up was 68 (range 18-203) months, and the mean dose was 66.7 (66-74) Gy. Median follow-up of patients undergoing pelvic nodal radiotherapy $(n=128)$ was 49 (19-159) months, with a mean local and pelvic dose of 66.9 (65-74) Gy and 48.3 (45-50.4) Gy respectively. Patient characteristics are summarised in Table 1.

Early GI side effects $\geq$ grade 2 were detected in $26 \%$ (115/447) and in $42 \%(54 / 128)$ of patients receiving local or pelvic radiotherapy respectively $(p=0.0004)$. Early GU side effects $\geq$ grade 2 (maximal rates) were detected in $15 \%$ $(69 / 447)$ and $16 \%(20 / 128)$ of patients with local or pelvic radiotherapy respectively $(p=0.96)$. The early GI and GU sideeffects rates, by grade, are given in Table 2 .

Late GI adverse events $\geq$ grade 2 were detected in $14 \%$ $(63 / 447)$ of patients receiving local, and in $14 \%(18 / 128)$ of patients receiving pelvic radiotherapy $(p=0.77)$. The corresponding 5-year actuarial incidence rates were $14 \%$ for both radiotherapy techniques; in contrast, the prevalence rates at 5 years were $2 \%$ and $0 \%$ (Fig. 1) respectively (n. s.). 
Table 1 Pretreatment and treatment-related patient characteristics

Table 2 Early gastrointestinal $(G I)$ and urogenital $(G U)$ adverse events separated in grades using the European Organization for Research and Treatment of Cancer (EORTC)/ Radiation Therapy Oncology Group (RTOG) classification

\begin{tabular}{|c|c|c|c|}
\hline & & $\begin{array}{l}\text { Local RT } n=447 \\
(\%)\end{array}$ & $\begin{array}{l}\text { Pelvic RT } n=128 \\
(\%)\end{array}$ \\
\hline \multirow[t]{2}{*}{$\overline{\text { Age (years) }}$} & Mean & 65 & 66 \\
\hline & Range & $45-82$ & $44-80$ \\
\hline \multirow[t]{4}{*}{ pT stage } & pT 2 & $183(41 \%)$ & $48(38 \%)$ \\
\hline & pT 3 & $230(51 \%)$ & $73(57 \%)$ \\
\hline & pT 4 & $27(6 \%)$ & $4(3 \%)$ \\
\hline & $\mathrm{T} X$ & $7(2 \%)$ & $3(2 \%)$ \\
\hline \multicolumn{4}{|l|}{$P S A(n g / m l)$} \\
\hline Prior to surgery & Average (min-max) & $13(0.21-290)$ & $22(1.2-1000)$ \\
\hline Post surgery & Average (min-max) & $0.23(0-7.18)$ & $0.26(0-4.3)$ \\
\hline Prior to $R T$ & Average (min-max) & $1.39(0-111.4)$ & $1.55(0-24.34)$ \\
\hline Gleason score & $2-6$ & $154(34 \%)$ & $16(12.5 \%)$ \\
\hline \multirow[t]{3}{*}{ (Based on surgery) } & 7 & $137(31 \%)$ & $45(35 \%)$ \\
\hline & $8-10$ & $78(17.5 \%)$ & $52(40.5 \%)$ \\
\hline & Unknown & $78(17.5 \%)$ & $15(12 \%)$ \\
\hline \multirow[t]{2}{*}{ Roach formula \% } & Mean & 16 & 25 \\
\hline & Range & $0-66$ & $0-100$ \\
\hline \multirow[t]{4}{*}{ Additional HT } & Yes & $174(39 \%)$ & $56(44 \%)$ \\
\hline & No & $271(60 \%)$ & $71(55 \%)$ \\
\hline & Orchiectomy & $1(0.5 \%)$ & $0(0 \%)$ \\
\hline & Unknown & $1(0.5 \%)$ & $1(1 \%)$ \\
\hline
\end{tabular}

$R T$ radiotherapy, $P S A$ prostate specific antigen, $H T$ hormone therapy

\begin{tabular}{lllll}
\hline & Local RT-GI & $\begin{array}{l}\text { Pelvic RT-GI } \\
n / \%\end{array}$ & $\begin{array}{l}\text { Local RT-GU } \\
n / \%\end{array}$ & $\begin{array}{l}\text { Pelvic RT-GU } \\
n / \%\end{array}$ \\
\hline Grade 0 & 153 & 22 & 199 & 41 \\
Grade 1 & $34 \%$ & $17 \%$ & $44 \%$ & $32 \%$ \\
& 179 & 52 & 179 & 67 \\
Grade 2 & $40 \%$ & $41 \%$ & $40 \%$ & $52 \%$ \\
& 113 & 53 & 66 & 20 \\
Grade 3 & $25 \%$ & $41 \%$ & $15 \%$ & $16 \%$ \\
& 2 & 1 & 3 & 0 \\
Grade 4 & $1 \%$ & $1 \%$ & $1 \%$ & $0 \%$ \\
& 0 & 0 & 0 & 0 \\
\hline
\end{tabular}

$R T$ radiotherapy, $G I$ gastrointestinal, $G U$ genitourinary, $n$ number of patients
Regarding severe (grade 3) toxicity, there were five events for local and two events for pelvic radiotherapy. All patients presented with persistent rectal bleeding and needed argon plasma coagulation of rectal wall telangiectasiae.

Late GU morbidity $\geq$ grade 2 was detected in $18 \%$ (80/447) of patients receiving local radiotherapy, compared to $24 \%(31 / 128)$ for pelvic radiotherapy $(p=0.001)$. The corresponding 5-year actuarial incidence rates were $16 \%$ and $35 \%$ respectively $(p=0.001)$, while the prevalence rates after 5 years were $6 \%$ and $8 \%$ respectively (Fig. 1; $p=0.6$ ). The late GI and GU side effects rates are displayed in Table 3, for each individual grade. Regarding severe (grade 3 ) toxicity, there were sixteen events for local and five events for pelvic radiotherapy. In the majority of events (90\%) urethral stricture following urethral extension occurred. Two patients required coagulation of severe telangiectasia. One patient developed a contracted bladder with low capacity following an ileal conduit urinary diversion (grade $4 \mathrm{GU}$ toxicity).

The mean duration ( \pm standard deviation) of late GI side effects $\geq$ grade 2 was $16.7 \pm 24.7$ months after local radiotherapy and $8.8 \pm 9.6$ months after pelvic radiotherapy $(p=0.10)$. The mean duration $( \pm$ standard deviation) of late GU side effects $\geq$ grade 2 was $16.0 \pm 24.1$ months after local radiotherapy and $11.9 \pm 17.9$ months after pelvic radiotherapy ( $p=0.39$ ). 
Fig. 1 Combination of actuarial incidence and prevalence rate of late gastrointestinal $(\mathrm{Gl})$ and genitourinary (UG) side effects $\geq$ grade 2 (European Organization for Research and Treatment of Cancer/Radiation Therapy Oncology Group classification) after prostate cancer radiotherapy (RT). The curve represents the actuarial incidence rate and the bars represent the prevalence of side effects at each follow-up visit. The constant increase in the incidence rate and the rather stable prevalence rates indicate that a constantly increasing number of patients is suffering from-however-mainly temporary side effects
Late gastrointestinal side effects (grade 2)

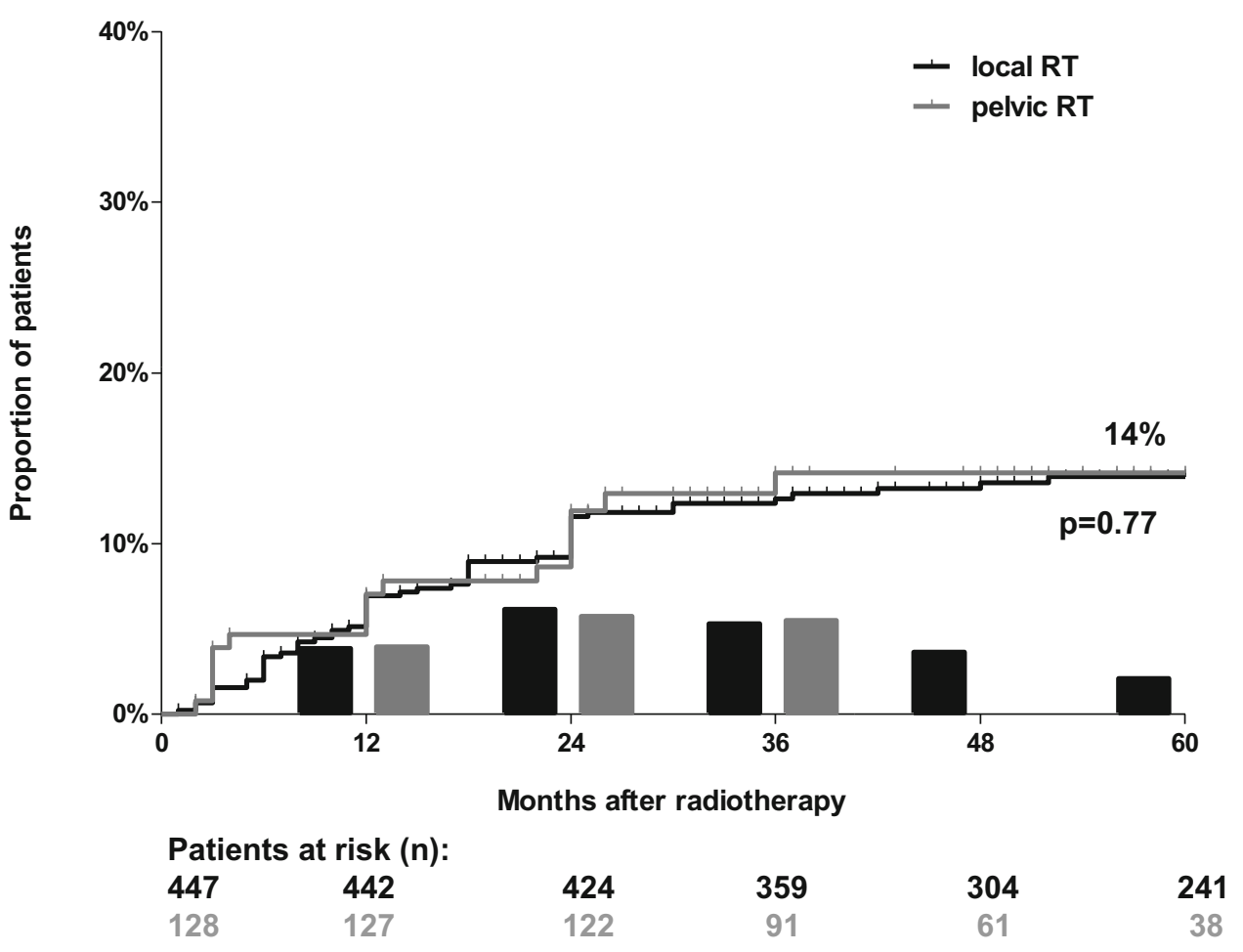

\section{Late urogenital side effects (grade 2)}

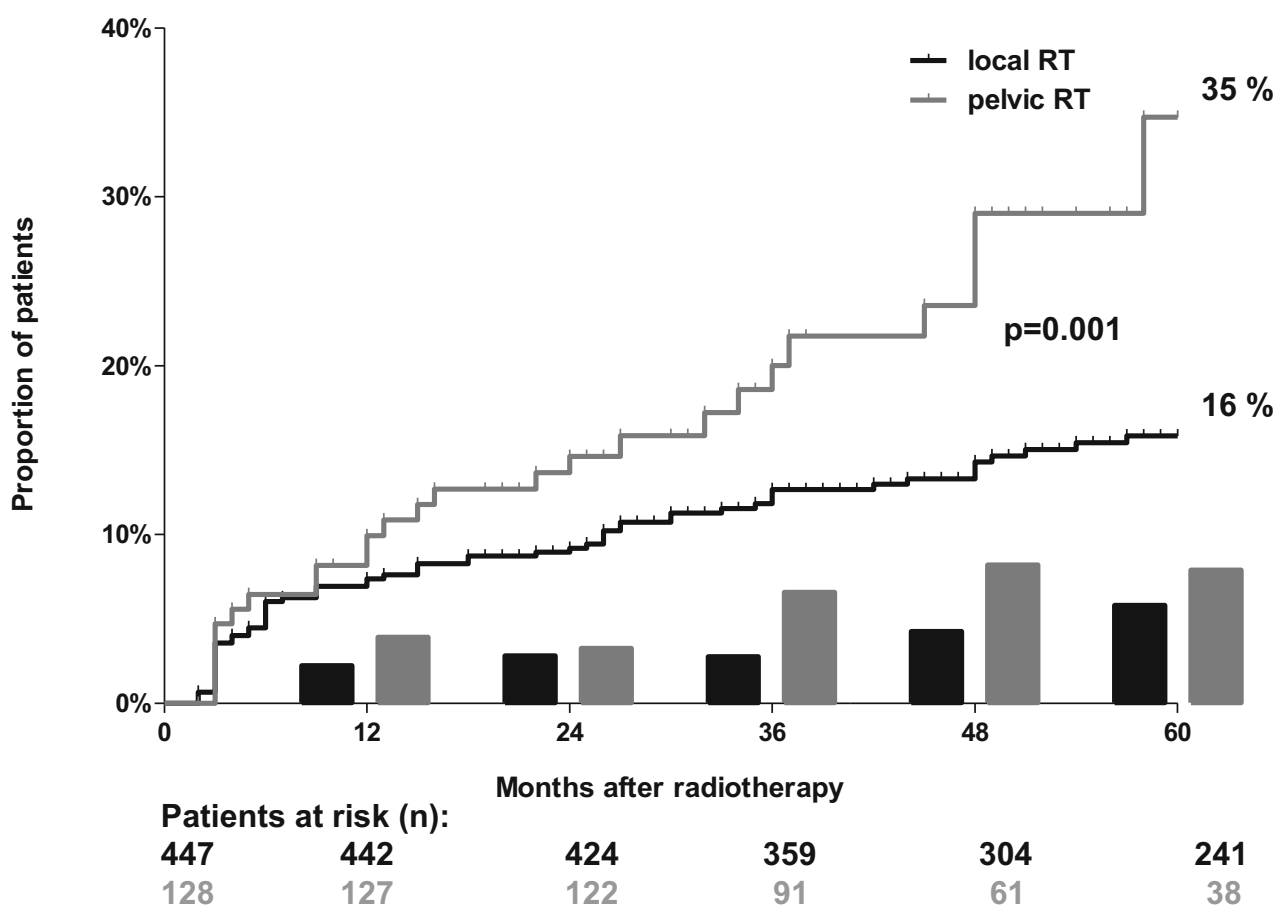


Table 3 Late gastrointestinal gastrointestinal (GI) and urogenital (GU) adverse events separated in grades using the Radiation Therapy Oncology Group/European Organization for Research and Treatment of Cancer classification

\begin{tabular}{lllll}
\hline & $\begin{array}{l}\text { Local RT-GI } \\
n / \%\end{array}$ & $\begin{array}{l}\text { Pelvic RT-GI } \\
n / \%\end{array}$ & $\begin{array}{l}\text { Local RT-GU } \\
n / \%\end{array}$ & $\begin{array}{l}\text { Pelvic RT-GU } \\
n / \%\end{array}$ \\
\hline Grade 0 & 292 & 70 & 258 & 72 \\
& $65 \%$ & $55 \%$ & $58 \%$ & $56 \%$ \\
Grade 1 & 92 & 40 & 109 & 25 \\
& $21 \%$ & $31 \%$ & $24 \%$ & $20 \%$ \\
Grade 2 & 58 & 16 & 64 & 25 \\
& $13 \%$ & $12 \%$ & $14 \%$ & $20 \%$ \\
Grade 3 & 5 & 2 & 16 & 5 \\
& $1 \%$ & $2 \%$ & $4 \%$ & $4 \%$ \\
Grade 4 & 0 & 0 & 0 & 1 \\
& $0 \%$ & $0 \%$ & $0 \%$ & $1 \%$ \\
\hline
\end{tabular}

$R T$ radiotherapy, $G I$ gastrointestinal, $G U$ genitourinary, $n$ number of patients

\section{Discussion}

In this study we investigated the incidence, prevalence, and duration of early and late side effects in postoperative patients with $\mathrm{PCa}$ after local versus pelvic radiotherapy. Our main finding was a significant difference for the incidence of early GI side effects ( $\geq$ grade 2 ) in patients receiving pelvic radiotherapy compared to patients receiving localonly radiotherapy $(42 \%$ versus $26 \%, p=0.0004)$. The incidence of late GI side effects ( $\geq$ grade 2 ) was, however, not significantly different between both groups (14\% versus $14 \%, p=0.77)$. Concerning GU side effects, no statistically significant difference for the incidence of early $\geq$ grade 2 side effects was detected between both groups $(15 \%$ versus $16 \%, p=0.96$ ). In contrast, the incidence of late GU morbidity $\geq$ grade 2 was significantly different with $18 \%$ in patients receiving local radiotherapy compared to $24 \%$ for pelvic radiotherapy $(p=0.001)$.

In general, the published data on early and late side effects of WPRT are inconclusive which is in line with the clinical controversy regarding this particular kind of therapy. In particular, data on postoperative radiotherapy are scarce. Two prior studies evaluated the incidence and prevalence of side effects in the setting of primary radiotherapy for PCa. In the prospective randomised trial RTOG 94-13 ( $70.2 \mathrm{~Gy}$ to the prostate and $50.4 \mathrm{~Gy}$ to the whole pelvis), a trend for higher rates of early and late grade $3 \mathrm{GI}$ complications in the WPRT combined with neoadjuvant and concurrent hormonal therapy arm was observed, without, however, reaching statistical significance, with $p=0.06$ and $p=0.09$ respectively [21]. In addition, in the updated 2007 RTOG analysis with a mean follow-up duration of 6.6 years, a higher risk for early and late morbidity was observed with a significantly higher incidence $(5 \%$ versus $1 \%, p=0.002$ ) of late grade 3 or higher GI reactions in the WPRT arm [31]. With the inclusion of lower-grade morbidity (grade 2 or higher), our study exhibited increased sensitivity for the detection of early GI and GU morbidity; this may have led to higher rates of side effects in our cohort.
An analysis by Aizer et al. [32], who administered 75.6 Gy to the prostate (4-field box/intensity-modulated radiotherapy, IMRT) and $45 \mathrm{~Gy}$ to the whole pelvis (4-field box), retrospectively investigated a cohort of 227 patients comparing WPRT and prostate-only radiotherapy (PORT). In agreement with our study, patients undergoing WPRT had increased early GI toxicity ( $p=0.048)$, but no significant difference in early GU toxicity $(p=0.09)$. No difference in late morbidities was observed, but the follow-up duration of that study (34 months for PORT and 25 months for WPRT patients) was more limited. However, as, postoperative RT patients are expected to have higher intestinal toxicities as such [33], it is difficult to compare both series with our study.

To the best of our knowledge, only a few studies compared WPRT and PORT toxicity in the postoperative setting. A retrospective analysis by Deville et al. [34] compared 36 patients treated with WPRT versus 31 patients treated with PORT using IMRT technique (70.2 Gy to prostate bed, $45 \mathrm{~Gy}$ to pelvic lymph nodes) and showed a significant increase in early GI side effects $(p=0.001)$, but no difference in acute GU and late GI/GU side effects. This small study had a limited median follow-up of 25 (12-44) months. Van Praet et al. [35] prospectively investigated 48 nodepositive patients treated with WPRT, combined with androgen deprivation and 239 node-negative patients treated with PORT (70.2 Gy to prostate bed, 45 Gy to pelvic lymph nodes). WPRT significantly increased early and late GI/GU side effects. Their study had a median follow-up of 24 (12-60) months for WPRT and 48 (12-56) months for PORT patients, which may have been a limitation in evaluating late toxicity.

Our study was specifically designed to evaluate GI and GU morbidity according to predefined, standardised criteria. At each follow-up visit, patients were interviewed by a study physician according to EORTC/RTOG criteria. This may have resulted in a more accurate and robust assessment of radiation side effects in a patient population that is gen- 
erally doing well clinically and may not report GI or GU disturbances on their own initiative.

Clinical manifestations of late urogenital side effects, as shown in our study, could be reduced by using advanced treatment techniques like IMRT or volumetric modulated arc radiotherapy (VMAT). Although it is necessary to include sensitive structures such as the prostatic urethra, trigonum vesicae and the bladder neck into the target volume, recent data suggest a reduction of urogenital morbidity with IMRT [36, 37]. Respecting normal tissue tolerances, IMRT and VMAT could more accurately spare organs at risk, especially the upper bladder, intestine, bowel and the rectal wall.

It is interesting to observe that long-term prevalence rates of radiation side effects (60 months after radiotherapy and onwards) remained at relatively low levels. This low prevalence rate in combination with a steadily rising actuarial incidence rate indicate that the majority of patients recovered from treatment-associated morbidity. Unlike other studies, we also investigated the duration of the complications. In relation to the typically long life-expectancy of $\mathrm{PCa}$ patients, the duration of side effects was generally short, and-moreover-not significantly associated with WPRT. In 2012, Schmid et al. [30] also demonstrated long-term recovery from GI and GU side effects after local-only radiotherapy.

\section{Limitations}

One of the limitations of our study is the disparity in terms of disease stage and follow-up periods of the two treatment groups, which is due to increasing referrals of patients with higher-risk disease in more recent periods. However, especially actuarial incidence rates are minimally affected by this difference in follow-up durations, especially as even in the WPRT group the median follow-up was 48 months. But still, some degree of sampling bias in the analysis of the long-term morbidity cannot be excluded with certainty. Moreover, treatment allocation (local versus pelvic radiotherapy) was not randomised; however, predefined risk-dependent criteria were used to allocate patients to the respective treatment modalities. Due to the naturally uneven distribution of disease characteristics in the patient population, the sample sizes of the two groups were not equal. A further limitation of this study is that systematic data on patient comorbidities are not available.

\section{Conclusion}

Our study demonstrates a statistically significant increase in early GI, and late GU, toxicities in patients undergoing adjuvant pelvic nodal radiotherapy for prostate cancer.
Advanced radiotherapy techniques may be instrumental in reducing or avoiding long-term morbidity in an active population with long-term survival perspectives.

Acknowledgements Open access funding provided by Medical University of Vienna.

Conflict of interest C. Waldstein, W. Dörr, R. Pötter, J. Widder and G. Goldner declare that they have no competing interests.

Open Access This article is distributed under the terms of the Creative Commons Attribution 4.0 International License (http:// creativecommons.org/licenses/by/4.0/), which permits unrestricted use, distribution, and reproduction in any medium, provided you give appropriate credit to the original author(s) and the source, provide a link to the Creative Commons license, and indicate if changes were made.

\section{References}

1. Valicenti RK, Thompson I Jr, Albertsen P, Davis BJ, Goldenberg SL, Wolf JS et al (2013) Adjuvant and salvage radiation therapy after prostatectomy: American Society for Radiation Oncology/ American Urological Association Guidelines. Int J Radiat Oncol Biol Phys 86:822-828

2. Budäus L, Schiffmann J, Graefen M, Huland H, Tennstedt P, Siegmann A et al (2017) Defining biochemical recurrence after radical prostatectomy and timing of early salvage radiotherapy. Strahlenther Onkol. https://doi.org/10.1007/s00066-017-1140-y

3. Bolla M, van Poppel H, Collette L, van Cangh P, Vekemans K, Da Pozzo L et al (2005) Postoperative radiotherapy after radical prostatectomy: a randomised controlled trial (EORTC trial 22911). Lancet 366:572-578

4. Thompson IM, Tangen CM, Paradelo J, Lucia MS, Miller G, Troyer D et al (2009) Adjuvant radiotherapy for pathological T3N0M0 prostate cancer significantly reduces risk of metastases and improves survival: long-term followup of a randomized clinical trial. J Urol 181:956-962

5. Wiegel T, Bottke D, Steiner U, Siegmann A, Golz R, Störkel S et al (2009) Phase III postoperative Adjuvant radiotherapy after radical prostatectomy compared with radical prostatectomy alone in pT3 prostate cancer with postoperative undetectable prostate-specific antigen: ARO 96-02/AUO AP 09/95. J Clin Oncol 27:2924-2930

6. Bolla M, van Poppel H, Tombal B, Vekemans K, Da Pozzo L, de Reijke TM et al (2012) Postoperative radiotherapy after radical prostatectomy for high-risk prostate cancer: long-term results of a randomised controlled trial (EORTC trial 22911). Lancet 380:2018-2027

7. Bottke D, Golz R, Störkel S, Hinke A, Siegmann A, Hertle L et al (2013) Phase 3 study of adjuvant radiotherapy versus wait and see in pT3 prostate cancer: impact of pathology review on analysis. Eur Urol 64:193-198

8. Moghanaki D, Koontz BF, Karlin JD, Wan W, Mukhopadhay N, Hagan MP et al (2013) Elective irradiation of pelvic lymph nodes during postprostatectomy salvage radiotherapy. Cancer 119:52-60

9. Spiotto MT, Hancock SL, King CR (2007) Radiotherapy after prostatectomy: improved biochemical relapse-free survival with whole pelvic compared with prostate bed only for high-risk patients. Int J Radiat Oncol Biol Phys 69:54-61

10. Morikawa LK, Roach M (2011) Pelvic nodal radiotherapy in patients with unfavorable intermediate and high-risk prostate cancer: evidence, rationale, and future directions. Int $\mathrm{J}$ Radiat Oncol Biol Phys 80:6-16 
11. Nguyen PL, D'Amico AV (2008) Targeting pelvic lymph nodes in men with intermediate- and high-risk prostate cancer despite two negative randomized trials. J Clin Oncol 26:2055-2056

12. Poelaert F, Fonteyne V, Ost P, De Troyer B, Decaestecker K, De Meerleer $\mathrm{G}$ et al (2017) Whole pelvis radiotherapy for pathological node-positive prostate cancer. Strahlenther Onkol 193:444-451

13. Walz J, Gallina A, Saad F, Montorsi F, Perrotte P, Shariat SF et al (2007) A Nomogram Predicting 10-Year Life Expectancy in Candidates for Radical Prostatectomy or Radiotherapy for Prostate Cancer. J Clin Oncol 25:3576-3581

14. Goldner G, Bombosch V, Geinitz H, Becker G, Wachter S, Glocker $S$ et al (2009) Moderate risk-adapted dose escalation with three-dimensional conformal radiotherapy of localized prostate cancer from 70 to 74 Gy. Strahlenther Onkol 185:94-100

15. Noldus J, Michl U, Graefen M, Haese A, Hammerer P, Huland $H$ (2002) Patient-reported sexual function after nerve-sparing radical retropubic prostatectomy. Eur Urol 42:118-124

16. Resnick MJ, Koyama T, Fan K-H, Albertsen PC, Goodman M, Hamilton AS et al (2013) Long-term functional outcomes after treatment for localized prostate cancer. N Engl J Med 368:436-445

17. Smeenk RJ, Hoffmann AL, Hopman WPM, van Lin ENJT, Kaanders JHAM (2012) Dose-Effect Relationships for Individual Pelvic Floor Muscles and Anorectal Complaints After Prostate Radiotherapy. Int J Radiat Oncol Biol Phys 83:636-644

18. Wilt TJ, Brawer MK, Jones KM, Barry MJ, Aronson WJ, Fox S et al (2012) Radical prostatectomy versus observation for localized prostate cancer. N Engl J Med 367:203-213

19. Zelefsky MJ, Levin EJ, Hunt M, Yamada Y, Shippy AM, Jackson A et al (2008) Incidence of Late Rectal and Urinary Toxicities After Three-Dimensional Conformal Radiotherapy and Intensity-Modulated Radiotherapy for Localized Prostate Cancer. Int J Radiat Oncol Biol Phys 70:1124-1129

20. Roach M (2004) In Reply. J Clin Oncol 22:2255-2257

21. Roach M, DeSilvio M, Lawton C, Uhl V, Machtay M, Seider MJ et al (2003) Phase III Trial Comparing Whole-Pelvic Versus ProstateOnly Radiotherapy and Neoadjuvant Versus Adjuvant Combined Androgen Suppression: Radiation Therapy Oncology Group 9413. J Clin Oncol 21:1904-1911

22. Roach M (1993) Re: The use of prostate specific antigen, clinical stage and Gleason score to predict pathological stage in men with localized prostate cancer, by A. W. Partin, J. Yoo, H. B. Carter, J. D. Pearson, D. W. Chan, J. I. Epstein and P. C. Walsh, J. Urol., 150: 110-114, 1993. J Urol 150:1923-1924

23. International Commission on Radiation Units and Measurements (1999) Prescribing, recording and reporting photon beam therapy. ICRU Report, vol. 62. ICRU, Bethesda

24. Cox JD, Stetz J, Pajak TF (1995) Toxicity criteria of the Radiation Therapy Oncology Group (RTOG) and the European organization for research and treatment of cancer (EORTC). Int J Radiat Oncol Biol Phys 31:1341-1346

25. Bentzen SM, Vaeth M, Pedersen DE, Overgaard J (1995) Why actuarial estimates should be used in reporting late normal-tissue effects of cancer treatment ... now! Int J Radiat Oncol Biol Phys 32:1531-1534

26. Christie D, Denham J, Steigler A, Lamb D, Turner S, Mameghan $\mathrm{H}$ et al (2005) Delayed rectal and urinary symptomatology in pa- tients treated for prostate cancer by radiotherapy with or without short term neo-adjuvant androgen deprivation. Radiother Oncol $77: 117-125$

27. Duchesne GM, Williams SG, Das R, Tai KH (2007) Patterns of toxicity following high-dose-rate brachytherapy boost for prostate cancer: Mature prospective phase I/II study results. Radiother Oncol 84:128-134

28. Haie-Meder C, Kramar A, Lambin P, Lancar R, Scalliet P, Bouzy $\mathrm{J}$ et al (1994) Analysis of complications in a prospective randomized trial comparing two brachytherapy low dose rates in cervical carcinoma. Int J Radiat Oncol Biol Phys 29:953-960

29. O'Brien PC, Hamilton CS, Denham JW, Gourlay R, Franklin CIV (2004) Spontaneous improvement in late rectal mucosal changes after radiotherapy for prostate cancer. Int J Radiat Oncol Biol Phys 58:75-80

30. Schmid MP, Pötter R, Bombosch V, Sljivic S, Kirisits C, Dörr W et al (2012) Late gastrointestinal and urogenital side-effects after radiotherapy-Incidence and prevalence. Subgroup-analysis within the prospective Austrian-German phase II multicenter trial for localized prostate cancer. Radiother Oncol 104:114-118

31. Lawton CA, DeSilvio M, Roach M III, Uhl V, Kirsch R, Seider M et al (2007) An Update of the Phase III Trial Comparing Whole Pelvic to Prostate Only Radiotherapy and Neoadjuvant to Adjuvant Total Androgen Suppression: Updated Analysis of RTOG 94-13, With Emphasis on Unexpected Hormone/Radiation Interactions. Int J Radiat Oncol Biol Phys 69:646-655

32. Aizer AA, Yu JB, McKeon AM, Decker RH, Colberg JW, Peschel RE (2009) Whole Pelvic Radiotherapy Versus Prostate Only Radiotherapy in the Management of Locally Advanced or Aggressive Prostate Adenocarcinoma. Int J Radiat Oncol Biol Phys 75:1344-1349

33. Cheng JC, Schultheiss TE, Nguyen KH, Wong JYC (2008) Acute Toxicity in Definitive Versus Postprostatectomy Image-Guided Radiotherapy for Prostate Cancer. Int J Radiat Oncol Biol Phys 71:351-357

34. Deville C, Vapiwala N, Hwang W-T, Lin H, Bar Ad V, Tochner $\mathrm{Z}$ et al (2012) Comparative Toxicity and Dosimetric Profile of Whole-Pelvis Versus Prostate Bed-Only Intensity-Modulated Radiation Therapy After Prostatectomy. Int J Radiat Oncol Biol Phys 82:1389-1396

35. Van Praet C, Ost P, Lumen N, De Meerleer G, Vandecasteele K, Villeirs G et al (2013) Postoperative high-dose pelvic radiotherapy for $\mathrm{N}+$ prostate cancer: Toxicity and matched case comparison with postoperative prostate bed-only radiotherapy. Radiother Oncol 109:222-228

36. Sveistrup J, af Rosenschöld PM, Deasy JO, Oh JH, Pommer T, Petersen PM et al (2014) Improvement in toxicity in high risk prostate cancer patients treated with image-guided intensity-modulated radiotherapy compared to 3D conformal radiotherapy without daily image guidance. Radiat Oncol 9:44

37. Zelefsky MJ, Kollmeier M, Cox B, Fidaleo A, Sperling D, Pei X et al (2012) Improved Clinical Outcomes With High-Dose Image Guided Radiotherapy Compared With Non-IGRT for the Treatment of Clinically Localized Prostate Cancer. Int J Radiat Oncol Biol Phys 84:125-129 